\title{
Structure integrated adaptronical systems for machine tools
}

\author{
C. Brecher - D. Manoharan - E. W. E. Stephan Witt
}

Published online: 15 March 2008

(C) German Academic Society for Production Engineering (WGP) 2008

Erratum to: Prod. Eng. Res. Devel.

DOI 10.1007/s11740-007-0074-0

Unfortunately, the spelling of one author's name was incorrect. The correct name should read D. Manoharan.

The online version of the original article can be found under doi:10.1007/s11740-007-0074-0.

C. Brecher · D. Manoharan $(\bowtie) \cdot$ E. W. E. Stephan Witt

Laboratory of Machine Tools and Production Engineering,

Steinbachstraße 19, 52074 Aachen, Germany

e-mail: d.manoharan@wzl.rwth-aachen.de 